\title{
Freeze-dried poly(D,L-lactic acid) macroporous guidance scaffolds impregnated with brain-derived neurotrophic factor in the transected adult rat thoracic spinal cord
}

\author{
Carla M. Patist ${ }^{(1)}$, Mascha Borgerhoff Mulder ${ }^{(1)}$, Sandrine E. Gautier ${ }^{(2),(3)}$, Veronique Maquet ${ }^{(2),(3)}$, Robert \\ Jérôme $^{(2),(3)}$, Martin Oudega ${ }^{(1),(4)}$ \\ (1) The Miami Project to Cure Paralysis, University of Miami School of Medicine, PO Box 016960, R-48, Miami, \\ FL 33136, USA \\ ${ }^{(2)}$ Center for Education and Research on Macromolecules (CERM), University of Liège, Sart-Tilman, 4000 \\ Liège, Belgium \\ (3) Interfacultary Center for Biomaterials, University of Liège, Sart- Tilman, 4000 Liège, Belgium \\ (4) Department of Neurological Surgery, University of Miami School of Medicine, Miami, USA
}

\begin{abstract}
The effects of poly(D,L-lactic acid) macroporous guidance scaffolds (foams) with or without brain-derived neurotrophic factor (BDNF) on tissue sparing, neuronal survival, axonal regeneration, and behavioral improvements of the hindlimbs following implantation in the transected adult rat thoracic spinal cord were studied. The foams were embedded in fibrin glue containing acidic-fibroblast growth factor. One group of animals received fibrin glue with acidic-fibroblast growth factor only. The foams were prepared by a thermally induced polymer-solvent phase separation process and contained longitudinally oriented macropores connected to each other by a network of micropores. Both foams and fibrin only resulted in a similar gliotic and inflammatory response in the cord-implant interfaces. With BDNF foam, up to 20\% more NeuN-positive cells in the spinal nervous tissue close to the rostral but not caudal spinal cord-implant interface survived than with control foam or fibrin only at 4 and 8 weeks after implantation. Semithin plastic sections and electron microcopy revealed that cells and axons more rapidly invaded BDNF foam than control foam. Also, BDNF foam contained almost twice as many blood vessels than control foam at 8 weeks after implantation. Tissue sparing was similar in all three implantation paradigms; approximately $42 \%$ of tissue was spared in the rostral cord and approximately $37 \%$ in the caudal cord at 8 weeks post grafting. The number of myelinated and unmyelinated axons was low and not different between the two types of foams. Many more axons were found in the fibrin only graft. Serotonergic axons were not found in any of the implants and none of the axons regenerated into the caudal spinal cord. The behavioral improvements in the hindlimbs were similar in all groups. These findings indicated that foam is well tolerated within the injured spinal cord and that the addition of BDNF promotes cell survival and angiogenesis. However, the overall axonal regeneration response is low. Future research should explore the use of poly(D,L-lactic acid) foams, with or without axonal growth-promoting factors, seeded with Schwann cells to enhance the axonal regeneration and myelination response.
\end{abstract}

Keywords: CNS regeneration; BDNF; poly( $\alpha$-hydroxyacid); Biodegradable; Polymer; Spinal cord injury

\section{Introduction}

Injury to the adult mammalian spinal cord sets off a process known as secondary injury; a cascade of pathophysiological events that results in loss of nervous tissue (secondary tissue loss), neuronal cell death, and damage of spinal and supraspinal axonal circuitries [1-3]. In humans, injury-induced tissue loss may result in the formation of cavities that often extend across the diameter of the cord leaving only a small rim of spinal white matter [4,5]. The lack of spontaneous regeneration of severed axons and the presence of cystic cavities prevent the formation of new functional synaptic connections, and, consequently, recovery of lost neurological function. Clinically, the prospects are poor. In the USA alone, each year over 10,000 newly injured people are added to the total of more than 250,000 , which are confined to their wheelchair.

One approach to promote axonal regeneration in the injured spinal cord, which has been investigated extensively, is the grafting of three-dimensional cellular transplants bridging the injury gap or cyst (e.g., Schwann cells, peripheral nerves; olfactory ensheathing cells; reviewed by [6-8]). Many of these repair strategies limit spinal tissue loss [9,10], promote regeneration/ sparing of spinal and supraspinal axons [9-13], and result in some functional recovery [9-18].

Due to the ongoing (secondary) tissue loss following an injury, it seems inevitable that repair of the (sub-) chronically injured cord will require strategies that include the transplantation of cellular grafts to replace lost spinal nervous tissue. Moreover, in cord injuries that have resulted in substantial nervous tissue loss, it may be 
necessary to implant a tubular guidance scaffold that may be a cellular transplant that reconnects the spinal cord stumps. The efficacy of tubular implants in combination with Schwann cells has been widely investigated (reviewed by [6,19-21]). Following grafting into the transected spinal cord, a SC bridge contained in a polymer tubular scaffold promotes regeneration and myelination of damaged axons [22,23]. Combining a SC graft with a neuroprotective agent [24] or growth factors [25-27] enhances the overall axonal growth response.

In the abovementioned studies, the SC bridge was contained within a non-degradable polyacrylnitril/polyvinylchloride (PAN/PVC) scaffold. The presence of such a tubular device is thought to prevent the formation of scar tissue, allows for accumulation of axonal growth-promoting molecules, and serves as a protective casing for the implant. These properties are especially beneficial early in the regeneration response. However, the presence of a non-degradable tubular device may become harmful to the overall regeneration response due to constriction of the spinal cord ends or foreign body reaction, which may develop over the long term. For these reasons, the efficacy of polymer implants in the injured spinal cord has been explored [28-32]. Our group has focused on the use of biodegradable synthetic aliphatic poly(a-hydroxyacids) for spinal cord repair [28,29]. Aliphatic poly( $\alpha-$ hydroxyacids) have been used repeatedly as guidance channels for regeneration in the peripheral nervous system [33]. They are biocompatible and easy to manage [20,28].

We demonstrated that poly(D,L-lactic acid) and the breakdown products are compatible with Schwann cell proliferation and differentiation in vitro [28]. We subsequently showed that poly(D,L-lactic acid) single-channel tubular scaffolds containing Schwann cells implanted into the transected adult rat thoracic spinal cord results in axonal regeneration and myelination [29]. However, it was also observed that in time these single-channel scaffolds would collapse and that this change in geometry was detrimental to the axonal regeneration response. From these results we concluded that the use of a polymer scaffold that retains the appropriate mechanical, geometrical and permeability properties over time would be beneficial for the regenerative response.

We have used poly(D,L-lactic acid) macroporous scaffolds (foams) of which the fabrication and characterization were described earlier [34,35]. Earlier, grafting of 14-20 rods made of the same material and embedded in fibrin glue containing acidic fibroblast growth factor was shown to promote axonal regeneration [34,35]. For this study, foams (diameter $2.6 \mathrm{~mm}$; same as adult rat thoracic spinal cord) were made with or without incorporation of the neurotrophic factor, brain-derived neurotrophic factor (BDNF). BDNF was chosen in combination with the foam because of its effects on cell survival [36-39] and axonal regeneration [18,27,40-42]. Following implantation, we have evaluated the effects of the foams on tissue sparing, neuronal survival, axonal regeneration, and behavioral improvements of the hindlimbs in the transected adult rat thoracic spinal cord.

\section{Materials and methods}

\subsection{Animals}

Female Fischer rats ( $n=49 ; 140-160 \mathrm{~g}$; Charles River Laboratories, Wilmington, NC) were housed according to NIH and USDA guidelines. The Institutional Animal Care and Use Committee of the University of Miami approved all animal procedures. For these experiments, female rats were used rather than male rats because of the easier maintenance following spinal cord transection. Before surgery, rats were anesthetized with rat cocktail, a mixture $(0.06 \mathrm{ml} / 100 \mathrm{~g}$ body weight) of ketamine $(42.8 \mathrm{mg} / \mathrm{ml})$, xylazine $98.6 \mathrm{mg} / \mathrm{ml})$ and ace-promazine $(1.4$ $\mathrm{mg} / \mathrm{ml})$. The backs were shaved and aseptically prepared with Betadine. Lacrilube ophthalmic ointment (Allergen Pharmaceuticals, Irvine, CA) was applied to the eyes to prevent drying and Bicillin $(0.02 \mathrm{ml} / 100 \mathrm{mg}$ body weight, $300 \mathrm{U} / \mathrm{ml}$; J. Buck, Inc., Owings Mills, MO) was administered intramuscularly. During surgery the animals were kept on a heating pad to maintain the body temperature of $39 \pm 0.5^{\circ} \mathrm{C}$.

\subsection{Preparation of the poly ( $\alpha$-hydroxyacid) macroporous tubular scaffolds (foam)}

One gram of poly(D,L-lactide) PLA (Resomer ${ }^{\circledR}$ R-206; Mn: 50,000, Boehringer-Ingelheim, Germany) and 50 $\mathrm{mg}$ of poly(D,L-lactide- $b$-ethylene oxide) $4 \mathrm{k}-4 \mathrm{k}$ copolymer (Mn: 10,000, CERM, Liege, Belgium) were dissolved in $10 \mathrm{ml}$ dimethylcarbonate (DMC, Acros) and filtered over $0.45 \mu \mathrm{m}$ : Next, $25 \mu \mathrm{g}$ BDNF (Promega, Madison, WI) was dissolved in $2.5 \mathrm{ml}$ of a filtered BSA solution $(2 \mathrm{mg} / \mathrm{ml})$. The solution was lyophilized and grounded to a fine powder. The BDNF/BSA powder was gently dispersed in $5 \mathrm{ml}$ of the polymer solution in $\mathrm{DMC}$ within a $50 \mathrm{ml}$-round bottom flask. This solution was frozen with liquid nitrogen and freeze-dried by vacuum sublimation for $72 \mathrm{~h}$ at $-10^{\circ} \mathrm{C}$, for $5 \mathrm{~h}$ at $0^{\circ} \mathrm{C}$, and finally at room temperature until it reached a constant weight. The fabrication as well as the in vitro degradation characteristics of the polymer foam was described previously [34,35]. Using a metal trephine with an inner diameter of $2.6 \mathrm{~mm}, 1 \mathrm{~cm}$ long rods were cut from the polymer foam following the longitudinal direction of the pores. The rods were sterilized by UV exposure under a laminar flow for $15 \mathrm{~min}$. These sterilized rods were kept at $-80^{\circ} \mathrm{C}$ until use. Just before surgery, the rods were thawed, cut into $4 \mathrm{~mm}$ long segments, and kept in Dulbecco's Minimal Essential Medium until implantation. Control foams were prepared using the same procedure but without addition of BDNF. 


\subsection{Implantation of the biodegradable foam}

Following a laminectomy at the T8-9 vertebral level, the dura mater was carefully opened. The exposed spinal cord (T9-10 level) was completely transected and $4 \mathrm{~mm}$ of tissue removed. All spinal roots visible within the transection gap were removed. After hemostasis was achieved, a single $4 \mathrm{~mm}$ long rod of foam (diameter of the rod is similar as diameter of spinal cord; $2.6 \mathrm{~mm}$ ) with or without BDNF was implanted in between the rostral and caudal spinal cord stumps. The scaffold was embedded in $1 \%$ fibrin glue containing acidic fibroblast growth factor (FGF1). The glue contained 1\% fibrinogen (Type 1 from human plasma; Sigma), $2 \% \mathrm{CaCl}_{2}, 2 \%$ gentamicin (Gemini Bioproducts, Inc., Calabasas, CA) 2\% aprotinin (Sigma), and FGF1 (2 $\mu \mathrm{g} / \mathrm{ml}$; Sigma). FGF1 was added to limit additional spinal tissue loss $[43,44]$ and to serve as a soft intermediate between the cord stumps and the implant. The injury area was rinsed with sterile saline supplemented with $0.1 \%$ gentamicin (Sigma). After the overlying muscles and skin were sutured separately, the animals received 10 ml Ringers' solution subcuteously. The rats were then placed in warmed cages with food and water readily available. To prevent urinary tract infection, Bicillin was administered 3,6 and 9 days post-surgery. The bladders were expressed manually two times a day until voluntary bladder release returned. In case urinary tract infection occurred, $0.05 \mathrm{ml}$ Baytril was administered (i.m.) twice a day for 7 days.

In total, 15 rats received a $1 \%$ fibrin only implant $(n=3$ for 1 week, $n=3$ for 4 weeks, and $n=9$ for 8 weeks survival), 15 rats received a control foam implant

( $n=3$ for 1 week, $n=3$ for 4 weeks, and $n=9$ for 8 weeks survival), and 15 rats received a fibrin only implant ( $n=3$ for 1 week, $n=3$ for 4 weeks, and $n=9$ for 8 weeks survival).

\subsection{Retrograde neuronal tracing}

Eight weeks after implantation, the spinal cord distal to the injury/implantation site was re-exposed and a total of $0.6 \mathrm{ml}$ of a $2 \%$ aqueous fast blue solution (FB, Sigma) was injected $7 \mathrm{~mm}$ distal to the distal implant-spinal cord interface (between vertebrae T10 and T11) using a glass needle (diameter was approximately $150 \mu \mathrm{m}$ ) attached to a $1 \mathrm{ml}$ Hamilton syringe. With the help of a micromanipulator, four $0.15 \mu 1$ injections were made $0.6 \mathrm{~mm}$ lateral to the dorsal sulcus at 1 and $2 \mathrm{~mm}$ deep (bilaterally) into the spinal cord. Each injection was carried out over a $3 \mathrm{~min}$ period and the needle was kept in place for an additional $3 \mathrm{~min}$ after each injection to prevent leakage of the tracer during withdrawal of the needle. After the injections, the muscle layers were closed separately, the skin closed with metal wound clips and the rat returned to her cage.

\subsection{Assessment of behavioral performance}

In rats that survived for 8 weeks, changes in hindlimb function were assessed using the Basso, Beattie, and Bresnahan-test (BBB-test $[67,68]$ ), an open field test with a 21-point scale. The BBB-test distinguishes between movements of individual components of the hindlimb. During the week before surgery the rats were tested twice to become accustomed to the test and the testing environment. During survival after surgery, rats were tested once a week for $4 \mathrm{~min}$ by two independent observers who were oblivious of the experimental paradigms.

\subsection{Histological procedures}

Two, 4, and 8 weeks after implantation, animals were deeply anesthetized with rat cocktail $[0.06 \mathrm{ml} / 100 \mathrm{~g}$ body weight; ketamine $(42.8 \mathrm{mg} / \mathrm{ml})$, xylazine $98.6 \mathrm{mg} / \mathrm{ml})$ and acepromazine $(1.4 \mathrm{mg} / \mathrm{ml})$ ] and perfused transcardially with $150 \mathrm{ml}$ heparinized saline followed by $400 \mathrm{ml}$ of $4 \%$ PFA in PB (0.1 M, pH 7.4). The spinal cord was removed and post-fixed overnight in the same fixative at $4^{\circ} \mathrm{C}$. Next, the grafted area including $5 \mathrm{~mm}$ of the proximal and caudal spinal cord was dissected out and transferred to phosphate-buffered $30 \%$ sucrose except for a 1-mm thick section taken from the middle of the implant. This section was transferred to $2 \%$ glutaraldehyde with $3 \%$ sucrose in $\mathrm{PB}$ for at least $24 \mathrm{~h}$ at $4^{\circ} \mathrm{C}$, processed for plastic embedding, and then cut transversally $(1 \mu \mathrm{m}$ thick) on a Reichert-Jung ultra-microtome. These sections were stained with a $1 \%$ toluidine blue- $1 \%$ methylene blue- $1 \%$ sodium borate solution and used to analyze the tissue cable histology and to determine the number of myelinated axons and blood vessels in the implants. Of 2 animals of each group, ultra-thin transversal sections of the $1 \mathrm{~mm}$ tissue block were cut, stained with uranyl acetate and lead citrate, and examined with a Philips CM-10 transmission electron microscope.

The other tissue blocks were embedded in Tissue-Tek O.C.T. compound (Miles Laboratories) and cut longitudinally/horizontally on a cryostat. The $20 \mu \mathrm{m}$ thick sections were collected on gelatin-coated glass slides and stored at $4{ }^{\circ} \mathrm{C}$ until immunohistochemical and cresyl violet staining. 


\subsection{Immunostaining}

Cryostat sections were permeabilized with $0.3 \%$ Triton $\mathrm{X}-100$ in phosphate-buffered saline $(\mathrm{PBS} ; 0.1 \mathrm{~m}, \mathrm{pH}=$ 7.4) and then immuno-blocked with $10 \%$ normal goat serum in PBS at room temperature for 30min. Next, the sections were incubated overnight with the primary antibody diluted in PBS containing $10 \%$ NGS and $0.3 \%$ Triton X-100 in humidified boxes at $4{ }^{\circ} \mathrm{C}$. The following primary antibodies were used: polyclonal rabbit antibodies against glial fibrillary acidic protein (GFAP, 1:200; Incstar Corp., Stillwater, MN), S100 (1:200; Dakocorps, Carpinteria, CA), laminin (1:400, Sigma), serotonin (5-HT, 1:100; Incstar Corp.), and monoclonal antibodies directed against neurofilaments (NF; RT97, 1:5; Developmental Hybridoma bank), monocytes/macrophages (ED1; MCA341, 1:500; Sero-tec, Oxford, UK), chondroitin sulfate (CS-56, 1:100; Sigma), and neuronal nuclear-specific protein (NeuN [45]; MAB377, 1:100; Chemicon, Temecula, CA). Next, the sections were rinsed in PBS and incubated with fluorescein-conjugated goat anti-rabbit (1:200; Cappel/ Organ on Teknika Corp., Durham, NY) or rhodamine-conjugated goat anti-mouse (1:100; Cappel/Organon Teknika Corp.) antibodies at room temperature for $1 \mathrm{~h}$. Finally, the sections were washed with PBS, coverslipped with Cityfluor (UKC Chem. Lab., Canterbury, UK) and kept at $4{ }^{\circ} \mathrm{C}$ until analysis. Adjacent sections were stained for cresyl violet.

\subsection{Assessment of spared spinal tissue}

At 2, 4, and 8 weeks after implantation, the amount of spared spinal tissue in a $2 \mathrm{~mm}$ long cord segment adjacent to the rostral and caudal interface was determined in a blinded fashion in cresyl violet-stained $20 \mu \mathrm{m}$ thick horizontal cryostat sections. Using an image analysis system (Universal Imaging, West Chester, PA, USA), the area of damaged tissue ('infiltrated tissue' and "lost tissue') was determined in an average of 10 sections at 200 $\mu \mathrm{m}$ intervals extending the width of the cord. Infiltrated tissue was delineated by a noticeable change in the density of infiltrating small cells, which resembled neutrophils and lymphocytes, and the presence of healthy neurons, which were recognized by darkly stained Nissl bodies in their cytoplasm. Lost tissue (cavities) was easily recognized by the lack of tissue. The single measurement from all sections were summed and multiplied by 10 (every tenth section was analyzed) to give the total area of damaged tissue. The total volume of the area of damaged tissue was derived by means of numerical integration. This volume of damaged tissue was then subtracted from the volume of the $2 \mathrm{~mm}$ long segment of the spinal cord adjacent to the rostral and caudal cordgraft interface to determine the volume of the remaining healthy appearing spinal cord tissue (spared tissue). Finally, these numbers were expressed as the percentage of the mean volume of a $2 \mathrm{~mm}$ long cord segment (T9 level) from four normal uninjured rats.

\subsection{Quantification of the number of NeuN-positive cells at the spinal cord-implant interfaces}

The number of NeuN-positive cells was determined in a $200 \mu \mathrm{m}$ wide area located $0.5 \mathrm{~mm}$ from the graft-host cord interface in every tenth sections of the rostral and distal cord. The sections were examined under fluorescence microscopy using a 63 x objective. In addition, the number of NeuN-positive cells was determined in a comparable area in a normal, uninjured spinal cord $(n=3)$. The average number of NeuN-positive cells found in the injured/transplanted cords was expressed as a percentage of the average number found in the uninjured spinal cord.

\subsection{Quantification of the number of blood vessels and myelinated axons in the implant}

Transversal, semithin, toluidine blue-stained plastic sections were used to determine the number of blood vessels and myelinated axons at the midpoint of the implants. The sections were examined under light microscopy using a 63 x objective by moving a square grid (surface area: $0.028 \mathrm{~mm}^{2}$ ) from left to right and from top to bottom through the whole transverse section of the implants. Every blood vessel and every myelinated axon present within the confines of the grid were counted before the grid was moved to the next position.

\subsection{Statistical analysis}

One-way analysis of variance (ANOVA) followed by Fisher's protected least-significant difference (PLSD) test was used to determine statistical differences between the average number of axons and neurons as determined for each group. However, in case of unequal variance ( $F$ test), a nonparametric analysis (Kruskal-Wallis test followed by Mann-Whitney U-test) was used. The latter test was also used to determine whether differences between the average BBB score per group were statistically significant. A statistically significant difference was accepted at $p<0.05$. 


\section{Results}

\subsection{Foams}

Scanning electron microscopy revealed the longitudinal orientation of the pores along the cooling direction in the poly(D,L-lactic acid) foam (Fig. 1a). In a transverse section of the foam, macropores as well as micropores (with a diameter of $10 \mathrm{~mm}$ or less) could be observed (Fig. 1b). Although few large macropores of $>300 \mu \mathrm{m}$ in diameter were present, in general the diameter varied between 75 and $200 \mu \mathrm{m}$. The macro-pores were connected to each other by a network of micropores. There were no obvious differences between the control and BDNFfoams.

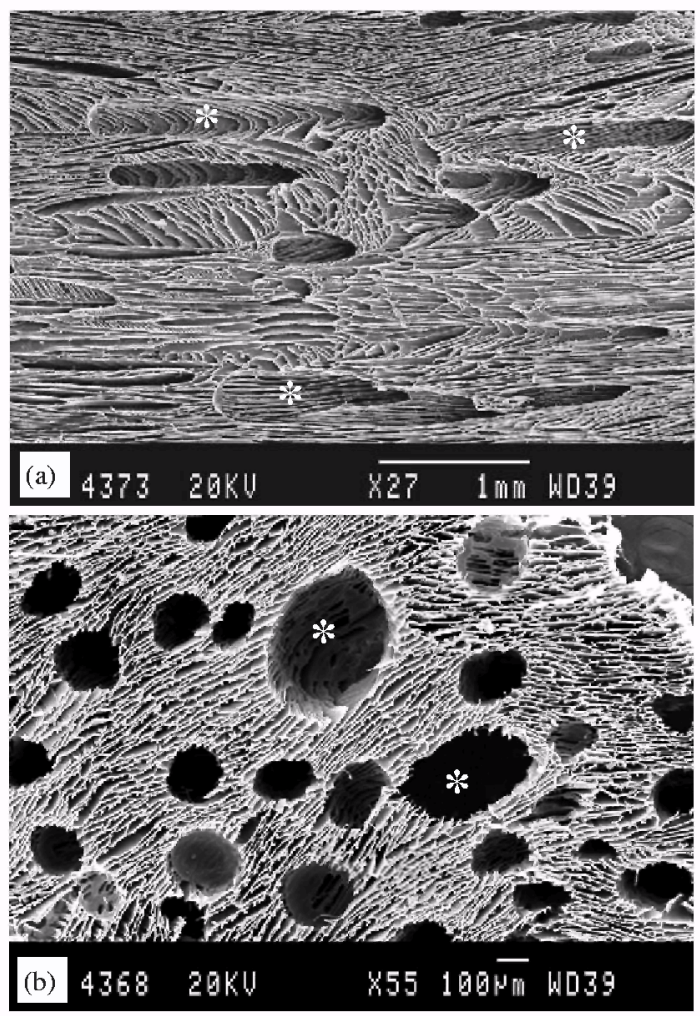

Fig. 1. Poly(D,L-lactic acid) foam contained pores oriented along the cooling direction. Scanning electron microscopy images of the foam, (a) Longitudinal section. asterisks are placed in some of the macropores, and (b) transversal section. asterisks are placed within two of the larger macropores (> $300 \mu \mathrm{m})$.

\subsection{Morphology and histology of the implants}

Transverse sections of the middle of the implants stained with toluidine blue revealed that cells had migrated into the periphery of the foams at 2 weeks after implantation, whereas the core of the foams contained only a few cells (Fig. 2a and b). A few layers of fibroblasts surrounded the foams (Fig. 2b) and blood vessels were present throughout the periphery of the foams. Sporadically a myelinated axons was observed (see below). Electron microscopy demonstrated the presence of fibroblasts, meningeal cells, Schwann cells (Fig. 2c), and a few macrophages. Fibrin and collagen fibrils were present especially in the cellular area at the periphery (Fig. 2c). Electron microscopy also revealed the presence of a sporadic unmyelinated axons (Fig. 2c). There was no difference in morphology and histology between the control foam and the BDNF-foam except that the BDNF foam contained more axons. The fibrin only implant at 2 weeks after implantation also contained most of the migrated cells in the periphery but many had also migrated into the core (Fig. 2d). The fibrin only implant was surrounded by several layers of fibroblasts (Fig. 2d). Fibrin and collagen fibrils, myelinated (Fig. 2e) and unmyelinated axons (Fig. 2f) were present throughout the implant.

At 4 weeks, more cells had migrated into the control foam, but the core was still not fully occupied (Fig. $2 \mathrm{~g}$ ). In contrast, by this time, the BDNF-foams were completely invaded by cells (Fig. 2h). Blood vessels were present throughout the foams. Very few myelinated axons were observed (see below). Electron microscopy revealed the presence of collagen fibrils in the cellular areas of both types of foam (Fig. 2i). Unmyelinated axons were present throughout both types of implants (Fig. 2i). At this time point, the fibrin only implant was largely similar to the fibrin implant at 2 weeks post implantation, although more cells had migrated into the core. Cells, collagen 
fibrils, myelinated and unmyelinated axons were present throughout the implant.

At 8 weeks after implantation, both types of foam were now completely invaded by cells (Fig. 2j). The implants contained blood vessels (Fig. 2k). Myelinated axons were rarely found (see below). Electron microscopy revealed the presence of collagen fibrils and unmyelinated axons throughout the foams (Fig. 21). There were no apparent differences between the two types of implants. The 8-week old fibrin only implants contained cells, fibrin and collagen fibrils, myelinated and unmyelinated axons.

\subsection{Host spinal cord-implant interface}

In all animals, some small cavities were present in the spinal tissue close to the implant-cord interface at 2 weeks after implantation (Fig. 3a). At 4 and 8 weeks after implantation, more and larger cavities were visible in the spinal cord tissue near the interface (Fig. 3b). There was no apparent difference in number or size of the cavities between animals that received the control or BDNF-foam with fibrin and animals that received fibrin only. At all time points, GFAP-positive reactive astrocytes were found in the spinal cord-implant border (Fig. 3c). At 4 and 8 weeks after implantation, some GFAP immunoreactivity was found within the control and BDNF foam (Fig. 3d). Some ED1-positive microglia/macrophages were found in the host spinal cord near the interface and in the implant at all time points. The distribution of the GFAP- and ED1-immunoreactivity was similar to that seen in other complete transection/transplantation paradigms, suggesting that the poly(D,L-lactic acid) foam did not provoked a gliotic and inflammatory response beyond what is normally seen [29]. Lamimin-positive blood vessels were found at the cord-implant interface and in the foam at all time points (Fig. 3e). More blood vessels were present in the BDNF foam at the longer survival time (see below). Chondroitin sulfate proteoglycan (CSPG) was expressed in the spinal tissue near the interface and in the foams where it appeared to be colocalized with laminin-positive blood vessels (Fig. 3f).
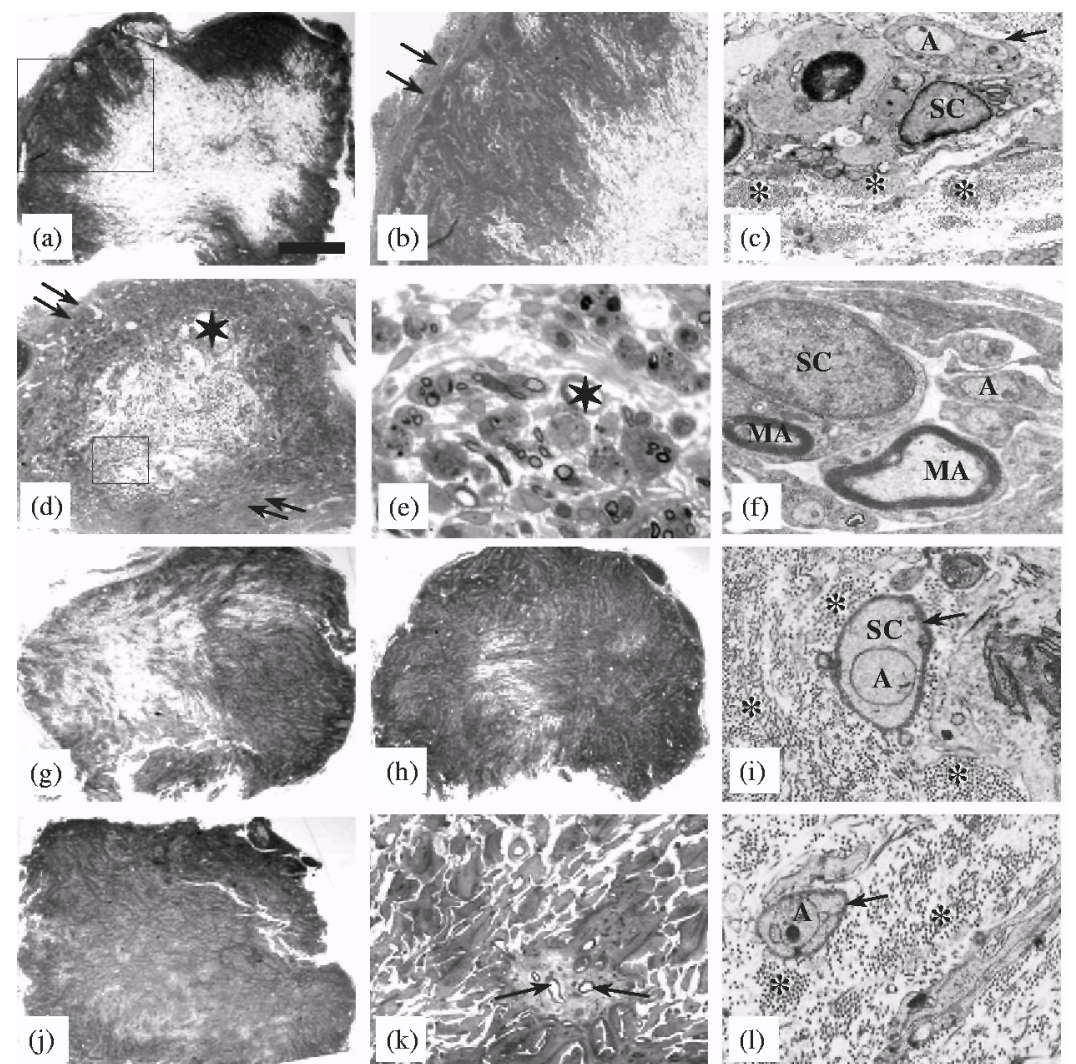

Fig. 2. Morphology and histology of the implants. (a) Transverse toluidine blue-stained semithin section through the midst of control foam 2 weeks after implantation. Note that cells have invaded the periphery but not the core of the foam, (b) Enlargement of the outlined area in (a). Arrows point at the fibroblast layers surrounding the foam, (c) Electron micrograph demonstrating the presence of a Schwann cell (SC) and an ensheated axon (A) in control foam 2 weeks after implantation. Asterisks indicate the presence of collagen fibrils. Arrow points at basal lamina, (d) Transverse toluidine blue-stained semithin section through the midst of a fibrin only implant 2 weeks after implantation. Note that more cells have invaded the core of the implant compared to control foam in (a). Arrows point at the fibroblast layers surrounding the implant. Star is placed in a blood vessel, (e) Outlined area in (d) showing myelinated axons and blood vessels (star) in the fibrin only implant, (f) Electron micrograph demonstrating the presence of a Schwann cell (SC), myelinated axons (MA), and unmyelinated axons (A) in a 
fibrin only implant 2 weeks after implantation, $(g)$ Transverse toluidine blue-stained semithin section through the midst of control foam 4 weeks after implantation. (h) Transverse toluidine blue-stained semithin section through the midst of BDNF foam 4 weeks after implantation. Note difference with control foam in (g); more cells have migrated into the core of the foam at this time point, (i) Electron micrograph showing a Schwann cell (SC) and an ensheated axon (A) in BDNF foam 4 weeks after implantation. Asterisks indicate collagen fibrils. The arrow points at basal lamina. (j) Transverse toluidine blue-stained semithin section through the midst of control foam 8 weeks after implantation. ( $k$ ) Transverse toluidine blue-stained semithin section demonstrating the presence of blood vessels in control foam at 8 weeks after implantation, (l) Electron micrograph demonstrating the presence of an ensheated axon (A) in BDNF foam 4 weeks after implantation. Asterisks indicate collagen fibrils and the arrow points at basal lamina. Bar represents $500 \mu \mathrm{m}$ ( $a, d, g, h$, and j), $200 \mu \mathrm{m}(b), 75 \mu \mathrm{m}(e, k)$, and $2 \mu \mathrm{m}(c, f$, $i, l)$.

\subsection{Tissue sparing was similar in all three paradigms}

At all time points after implantation, the tissue adjacent to the graft contained one or more cavities ("lost tissue '; Fig. 4a). In addition, close to the implant in gray as well as white matter we observed areas that were infiltrated by numerous small round cells, resembling neutrophils and lymphocytes ('infiltrated tissue'; Fig. 4b), which were devoid of healthy looking neuronal cell bodies (as analyzed using morphological criteria). The area of infiltrated and lost tissue together was, for quantification purposes, designated as "damaged spinal tissue'. The amount of spared spinal nervous tissue was determined in a $2 \mathrm{~mm}$ long segment of the spinal cord adjacent to the rostral and caudal cord-implant interface at 2, 4, and 8 weeks after implantation. First, the mean total volume of damaged tissue was determined, which was then subtracted from the mean volume of the analyzed segment to give the mean volume of spared tissue. This value was then expressed as the percentage of the mean volume of a comparable $2 \mathrm{~mm}$ long spinal cord segment at the T9 level in normal, uninjured, Fischer rats, which was $10.7 \pm 0.82 \mathrm{~mm}^{3}$ (SEM, $\left.n=4\right)$. In animals that received fibrin only, the volume of spared spinal tissue in the rostral cord stump was $75.4 \pm 7.5 \%(\mathrm{SEM}, n=6), 52.3 \pm 6.9 \%$, and $44.2 \pm 6.1 \%$ at 2,4 , and 8 weeks after implantation, respectively, of the volume in a normal uninjured rat (Fig. 4c). The volume of spared tissue in the rostral cord in rats with control foam was $77.6 \pm 8.7 \%$ (SEM, $n=7$ ), $50.1 \pm 5.8 \%$, and $42.2 \pm 7.5 \%$, and in rats with BDNF foam, $78.3 \pm 6.3 \%$ (SEM, $n=6$ ), $54.7 \pm 7.2 \%$, and $43.2 \pm 8.2 \%$ at 2,4 , and 8 weeks postimplantation, respectively, of the volume in a normal animal (Fig. 4c). In the caudal cord the volume of spared tissue (as a percentage of the volume in a normal, uninjured cord) in rats with fibrin only was $73.4 \pm 7.1 \%$ (SEM, $n=6), 48.3 \pm 7.4 \%$, and $38.2 \pm 8.8 \%$, in rats with control foam, $71.3 \pm 6.4 \%$ (SEM, $n=7), 44.4 \pm 6.7 \%$, and $39.3 \pm 7.5 \%$, and in rats with BDNF foam, $73.1 \pm 7.2 \%$ (SEM, $n=6$ ), $48.7 \pm 6.6 \%$, and $37.8 \pm 6.8 \%$ at 2 , 4, and 8 weeks post-implantation, respectively (Fig. 4d). This result demonstrate that a complete transection followed by implantation of fibrin only or foam results in substantial loss of spinal nervous tissue; up to $58 \%$ in the rostral cord and up to $63 \%$ in the caudal cord. In addition, implantation of foam with or without BDNF compared to fibrin only does not result in further loss of spinal nervous tissue. 

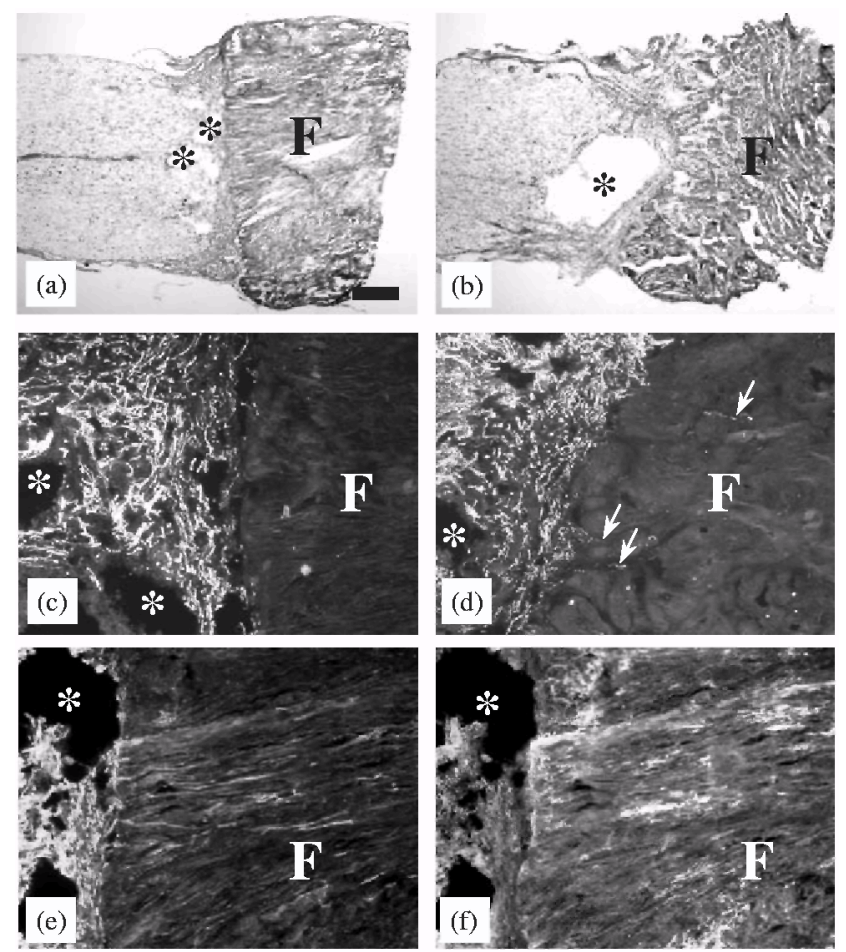

Fig. 3. Poly(D,L-lactic acid) foam were well integrated in the injured spinal cord. (a) Horizontal cresyl violetstained section demonstrating the presence of small cavities in the spinal cord near the interface with the foam (F) 2 weeks after implantation. Asterisks are placed within the cavities, (b) Same as (a) but showing a larger cavity near the cord-foam $(F)$ interface 4 weeks after implantation. Asterisk is placed within the cavity, $(c)$ GFAP-positive cells and processes in the spinal cord, but not in the foam $(F)$, at 2 weeks after implantation. Asterisks placed in cavities in spinal cord, (d) GFAP-positive processes (arrows) in control foam (F) at 4 weeks after implantation. Asterisk indicates a cavity in the spinal cord, (e) Laminin-positive profiles in BDNF foam (F) 8 weeks after implantation, (f) Same area as in (e) but demonstrating CSPG-immunoreactive profiles in BDNF foam $(F)$. Note the apparent colocalization of laminin and CSPG. Asterisks are placed in cavities in the spinal cord. Bar represents $600 \mu \mathrm{m}(a, b)$ and $150 \mu \mathrm{m}(c-f)$.

\subsection{Foams with BDNF promoted neuronal survival in the rostral spinal cord}

The number of NeuN-positive cells was quantified in the rostral and caudal stump in a $200 \mu \mathrm{m}$ wide area located $0.5 \mathrm{~mm}$ from the cord-implant interface at 2, 4 and 8 weeks after implantation. NeuN-positive cells in the rostral spinal cord at 8 weeks after implantation of control foam and in a normal uninjured spinal cord are depicted in Fig. 5a and b, respectively. At 4 and 8 weeks, but not at 2 weeks, implantation of BDNF foam resulted in a significantly $(p<0.05)$ higher number of NeuN-positive cells in the rostral but not in the caudal spinal cord compared to control foams or fibrin only. When the numbers were expressed as a percentage of the number found in comparable levels in the normal, uninjured spinal cord, implantation of fibrin only resulted in survival of $72.7 \pm 9.7 \%$ (SEM; $n=6$ ), $42.9 \pm 7.3 \%$, and $21.9 \pm 6.4 \%$, in the rostral cord at 2,4 , and 8 weeks after implantation, respectively (Fig. 5c). With control foam $(n=5)$ neuronal survival in the rostral cord was $75 . \pm$ $79.1 \%, 39.5 \pm 6.8 \%$, and $19.2 \pm 7.4 \%$, and with BDNF foam $(n=7) .73 .4 \pm 8.2 \%, 60.6 \pm 6.2 \%$, and $42.2 \pm 7.5 \%$ at 2,4 , and 8 weeks after implantation, respectively (Fig. 5c). Neuronal survival in the caudal cord was $63.3 \pm 6.2 \%$ (SEM; $n=6$ ), $35.2 \pm 7.3 \%$, and $17.3 \pm 8.9 \%$ with fibrin only, $60.8 \pm 7.8 \%, 40.4 \pm$ $7.8 \%$, and $19.9 \pm 10.4 \%$ with control foam $(n=5)$, and $66.5 \pm 7.5 \%, 39.2 \pm 9.9 \%$, and $23.4 \pm 9.1 \%$ with BDNF foam $ð n 1 / 47$ ); at 2, 4, and 8 weeks after implantation, respectively (Fig. 5d). These results indicate that in this transection/implantation paradigm addition of BDNF to the foam promotes cell survival near the rostral spinal cord-implant interface at 4 and 8 weeks after implantation. 

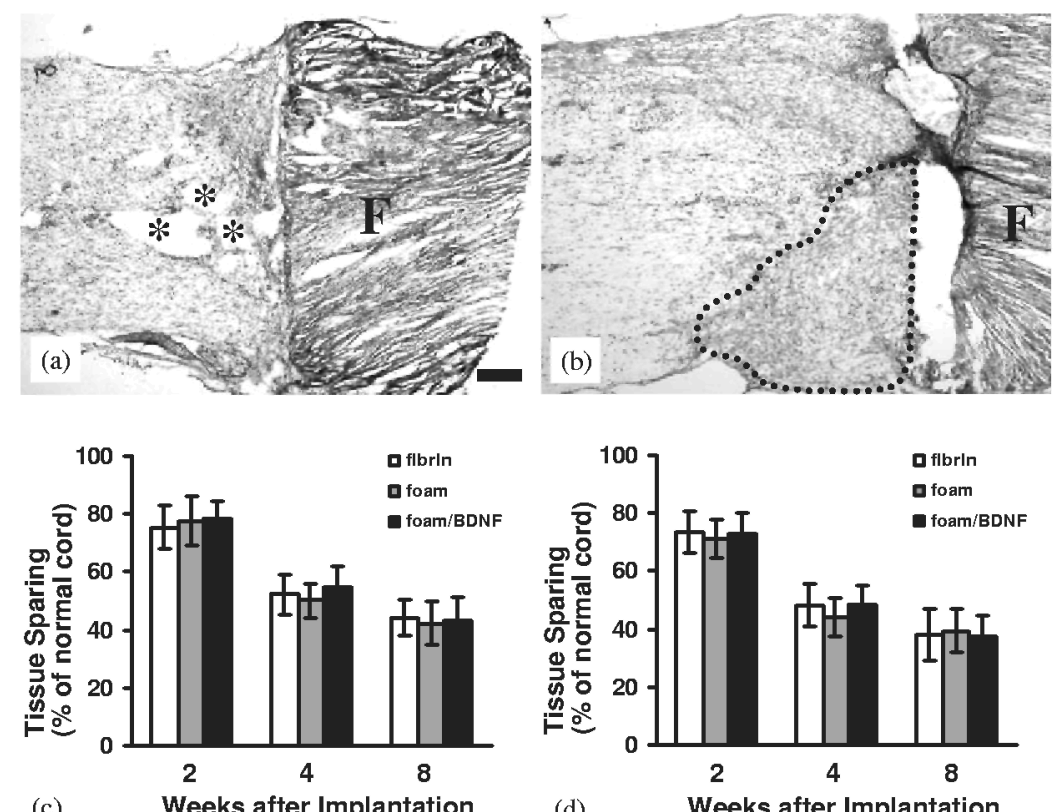

(c) Weeks after Implantation

(d)

Weeks after Implantation

Fig. 4. All implants resulted in similar sparing of spinal cord tissue. (a) Horizontal cresyl violet-stained section demonstrating the presence of several small cavities in the spinal cord near the interface with the foam $(F) 2$ weeks after implantation. Asterisks are placed within the cavities, (b) Horizontal cresyl violet-stained section demonstrating the presence of an area (outlined) near the cord-foam $(F)$ interface infiltrated with many small cells at 2 weeks after implantation, (c) Bar graph demonstrating tissue sparing (as \% of normal cord) in the rostral cord at 2, 4, and 8 weeks after implantation of fibrin only, control foam, and BDNF foam, (d) Bar graph demonstrating tissue sparing (as \% of normal cord) in the caudal cord at 2, 4, and 8 weeks after implantation of fibrin only, control foam, BDNF foam. Bar represents $500 \mu \mathrm{m}(a, b)$.
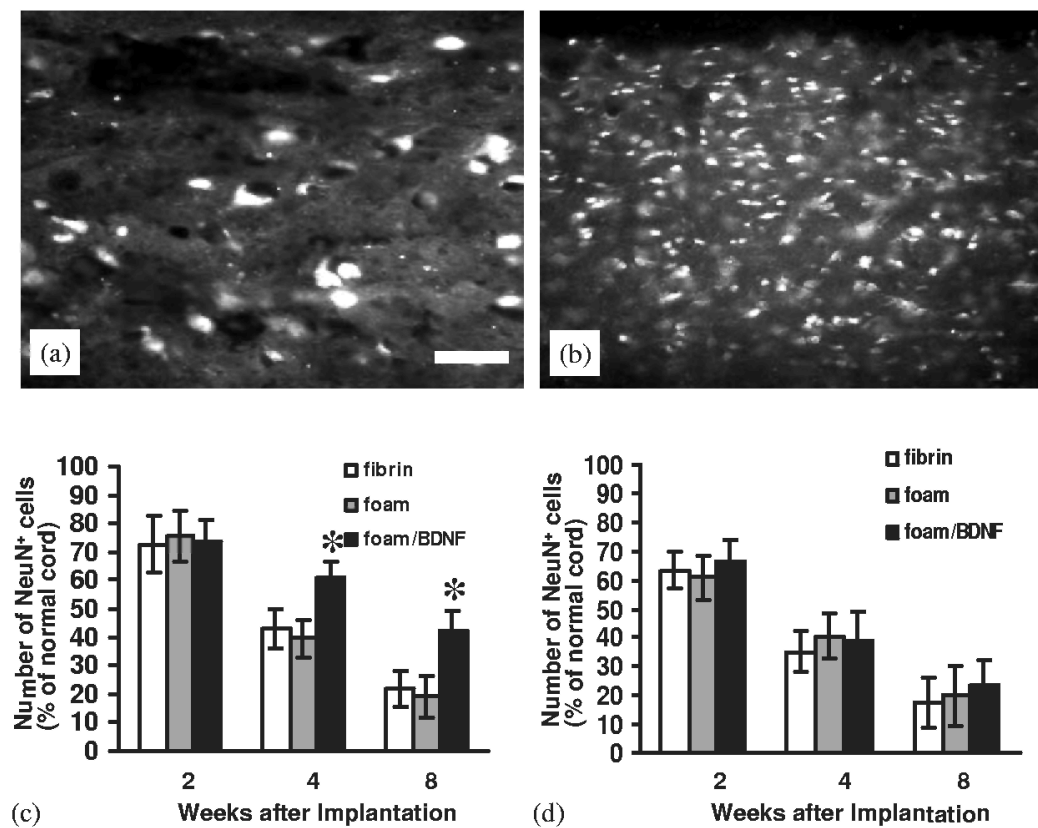

(c) Weeks after Implantation

$$
\begin{array}{lc}
2 & 4 \\
\text { Weeks after Implantation }
\end{array}
$$

Fig. 5. BDNF containing foam increased neuronal survival in the rostral spinal cord at 4 and 8 weeks after implantation. (a) Horizontal section showing NeuN-positive cells (neurons) in the gray matter $0.5 \mathrm{~mm}$ from the rostral cord-foam interface 2 weeks after implantation, (b) Horizontal section showing NeuN-positive neurons in gray matter at a comparable level as in (a) in the normal, uninjured spinal cord, (c) Bar graph demonstrating the number of NeuN-positive cells (as \% of normal cord) in the rostral cord at 2, 4, and 8 weeks after implantation of fibrin only, control foam, and BDNF foam. Cells were counted in a $200 \mu \mathrm{m}$ wide strip of tissue $0.5 \mathrm{~mm}$ away from the rostral cord-implant interface. Asterisk indicates a significant difference $(p<0.05)$ with fibrin only and control foam groups. (d) Bar graph demonstrating the number of NeuN-positive cells (as \% of normal cord) in the caudal cord at 2, 4, and 8 weeks after implantation of fibrin only, control foam, BDNF foam. 
Cells were counted in a $200 \mu \mathrm{m}$ wide strip of tissue $0.5 \mathrm{~mm}$ away from the caudal cord-implant interface. Bar represents $35 \mu \mathrm{m}(a, b)$.
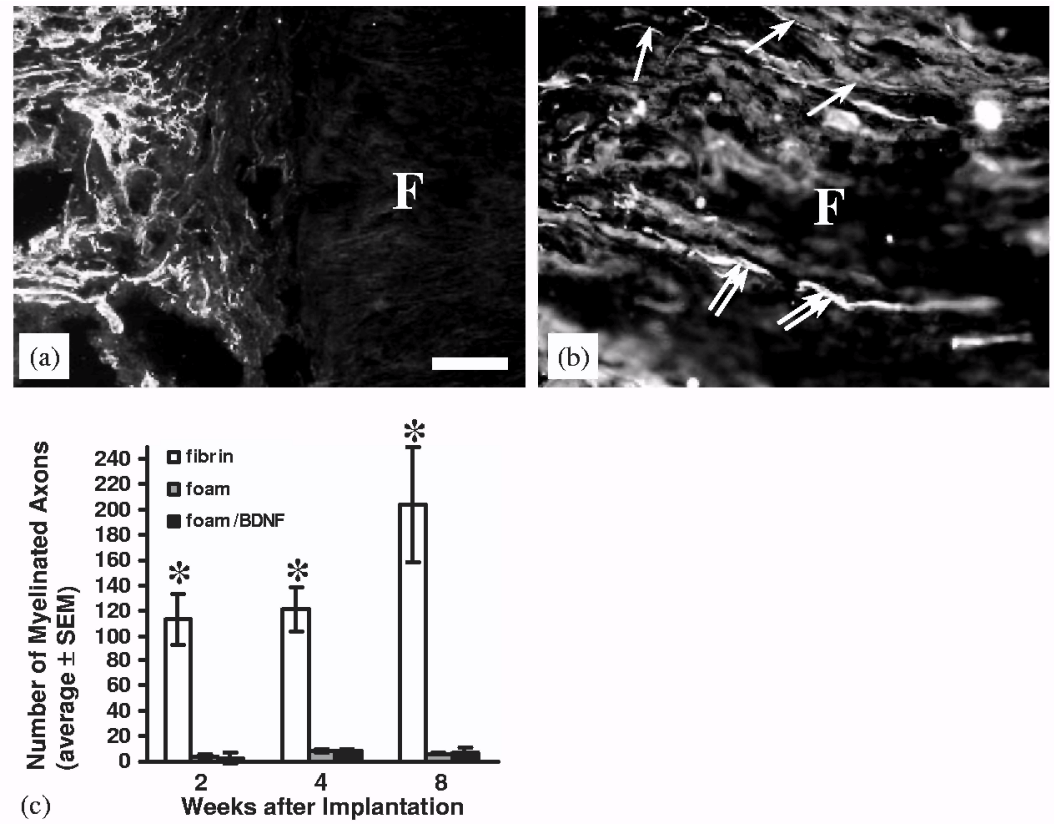

Fig. 6. NF-positive axons were present in the foam. (a) Horizontal section showing NF-positive axons in the spinal tissue but not in control foam $(F)$ at 2 weeks after implantation, (b) Horizontal section showing NFpositive axons within control foam $(F)$ at 4 weeks after implantation. (c) Bar graph demonstrating the average number ( \pm SEM) of myelinated axons within the midst of the fibrin only, control foam, and BDNF foam at 2, 4, and 8 weeks after implantation. Asterisk indicates a significant difference $(p<0.01)$ with both foam groups. Bar represents $200 \mu \mathrm{m}(\mathrm{a})$ and $50 \mu \mathrm{m}(\mathrm{b})$.

\subsection{Axons regenerated into the implants}

NF-positive axons were found within the fibrin only implant at all time points after implantation. Control foams did not contain NF-positive axons at 2 weeks after implantation (Fig. 6a). However, at 4 and 8 weeks after implantation NF-positive fibers (single or in small bundles) were observed within the foams (Fig. 6b). In contrast, in BDNF-foams, NF-positive axons were found at 2, 4, and 8 weeks after transplantation. These findings indicate that the addition of BDNF to the foam resulted in an earlier ingrowth of axons into the implant. Axons positive for 5-HT were not found within any of the implants, suggesting that the responding axons were not of serotonergic origin.

The number of myelinated axons in the implants was determined in 1- $\mu \mathrm{m}$ thick transverse sections taken from the middle of the implant. In animals that received fibrin only, $113 \pm 20$ (average $\pm S E M ; n=3$ ) were present 2 weeks after implantation, $121 \pm 18(n=3)$ at 4 weeks and $204 \pm 46(n=3)$ at 8 weeks (Fig. 6c). In control foam, $4 \pm 2(n=3)$ were present 2 weeks after implantation, $8.3 \pm 2.3(n=3)$ at 4 weeks and $5.5 \pm 0.5(n=3)$ at 8 weeks (Fig. 6c). In animals that received foams with BDNF, $3.3 \pm 1.2$ myelinated axons $(n=3)$ were present at 2 weeks, $8 \pm 1.2(n=3)$ at 4 weeks, and $7 \pm 1(n=3)$ at 8 weeks (Fig. $6 \mathrm{c})$. There was a statistical difference between the numbers of myelinated axons within the fibrin only and both foam implants at all time points $(\mathrm{p}<0.01)$. There were no statistical differences between the numbers of myelinated axons within the control and BDNF-foams at any time point. Clearly, the implantation of foam with or without BDNF does not result in substantial myelination of regenerating axons.

\subsection{Foams with BDNF improved angiogenesis}

Immunostaining for laminin revealed the presence of blood vessels within the implants at all time points studied (see Fig. 7a and b; see also Fig. 3e). In toluidine blue-stained sections, blood vessels could be readily identified in the implants at all time points (see also Fig. 2k). The number of blood vessels in the implants was determined in a $1 \mu \mathrm{m}$-thick transverse section taken from the middle of the implant. In animals that received fibrin only, $65 \pm$ 11 (average \pm SEM; $n$ 1/4 3) blood vessels were present at 2 weeks, $96 \pm 7(n 3)$ at 4 weeks, and $137 \pm 9(n=2)$ at 8 weeks post-grafting (Fig. 7c). In animals that received control foam, $18 \pm 1$ (average 7 SEM; $n=3$ ) blood vessels were present at 2 weeks, $23 \pm 2.3(n=2)$ at 4 weeks, and $31 \pm 1.5(n=3)$ at 8 weeks post-grafting (Fig. 
7c). In BDNF-foams, $22 \pm 4.3$ ðn $1 / 43 \mathrm{P}$ blood vessels were present at 2 weeks after implantation, $24.7 \pm 1.9(n=$ $3)$ at 4 weeks, and $58 \pm 4(n=3)$ at 8 weeks (Fig. 7c). At all time points, there was a statistical difference between the number of blood vessels in the fibrin only and the two foam groups $(p<0.01)$ : Also, there was a statistical difference between the numbers of blood vessels found in the BDNF-foam and the control foam $(p<0.05)$ at the 8 -week time point.
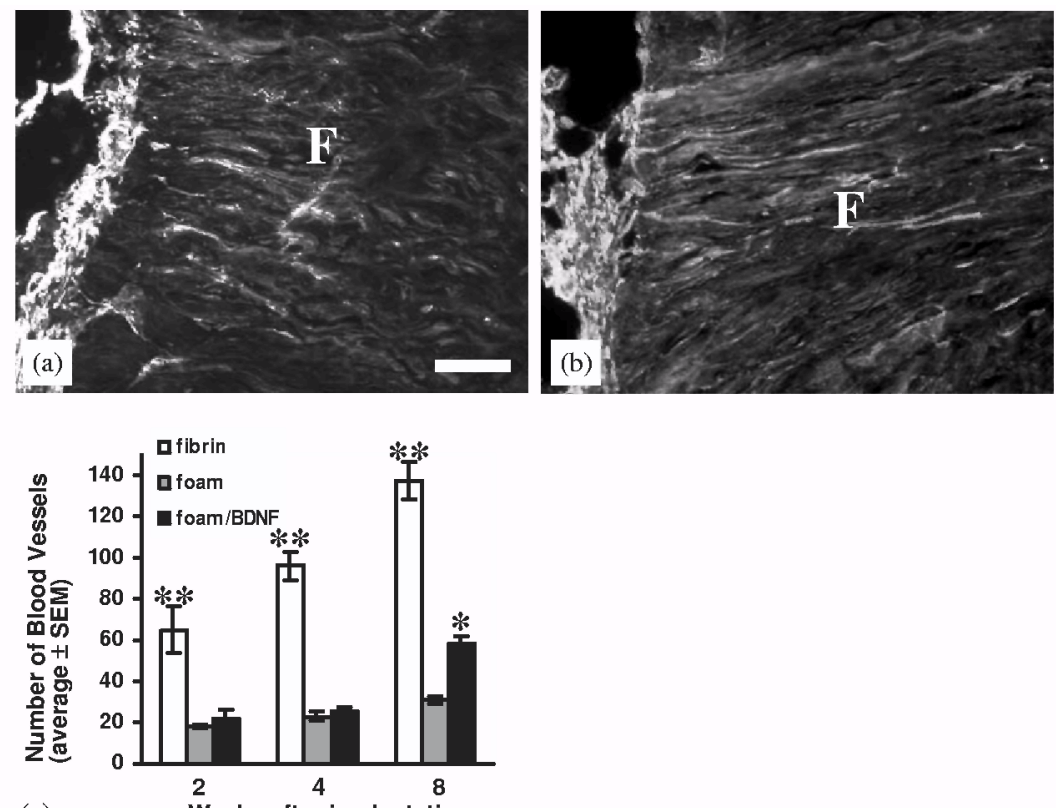

(c)

Weeks after implantation

Fig. 7. BDNF promoted the formation of blood vessels in the foam. (a) Laminin-positive profiles in BDNF foam $(F)$ at 4 weeks after implantation, (b) Laminin-positive profiles in BDNF foam $(F)$ at 8 weeks after implantation, (c) Bar graph demonstrating the average number ( \pm SEM) of blood vessels within the midst of the fibrin only, control foam, and BDNF foam at 2, 4, and 8 weeks after implantation. Double asterisks indicate a significant difference $(P<0.01)$ with both foam groups. Single asterisk indicates a significant difference $(p<0.05)$ between the BDNF and control foam group. Bar represents $150 \mu \mathrm{m}(a, b)$.

\subsection{Axons did not regenerate into the distal spinal cord}

Axonal regeneration across the fibrin only or foam implants and into the distal spinal cord was examined using retrograde FB neuronal tracing. In none of the animals retrogradely labeled neurons were found in the rostral spinal cord or brain, suggesting that axons were not regenerating from the implant into the distal spinal cord.

\subsection{Implants did not improve hindlimb performance}

All animals exhibited a gradual improvement in hindlimb locomotor function during the 8 weeks following implantation. Animals that received fibrin only reached a score of $5.8 \pm 0.6$ (average \pm SEM) at 8 weeks after implantation (Fig. 8). Animal with a control foam reached $5.7 \pm 0.6$ and with a BDNF-foam, $6.5 \pm 0.2$ at 8 weeks post grafting (Fig. 8). The BBB score of approximately 6 implies extensive movement of two hindlimb joints.

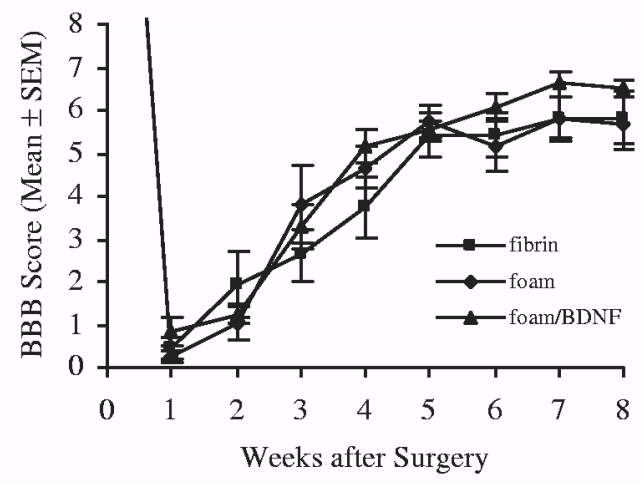

Fig. 8. Functional recovery of the hindlimbs was similar in all three implantation paradigms. Bar graph 
demonstrating the average ( \pm SEM) BBB scores during the 8 weeks of survival after implantation of fibrin only, control foam, and BDNF foam. Note that a similar gradual recovery in hind limb behavior is seen in all three implantation paradigms.

\section{Discussion}

In the present study we have explored the use of biodegradable macroporous guidance channels with or without BDNF in the completely transected adult rat spinal cord. The complete transection model has been used extensively over the last decade to explore the ability of cellular and non-cellular implants to promote axonal regeneration and functional recovery following spinal cord injury. This model is especially suitable because the axonal response is unquestionably due to regeneration, which allows for a clear interpretation of the ability of cells, materials, and growth factors to promote axonal regeneration in the injured spinal cord.

Implantation of foam with BDNF had a neuroprotective effect on neurons in the rostral but not caudal spinal cord. We found that up to $20 \%$ more NeuN-positive cells a short distance away from the rostral cord-implant interface survived at 8 weeks after implantation of the BDNF-foam compared with control foam and fibrin only. Following injury to the adult cord, (active) apoptotic and (passive) necrotic mechanisms contribute to cell death $[46,47]$. It has been shown previously that BDNF can rescue neurons from injury-induced death [36-39]. BDNF may exerts this neuroprotective effects through calmodulin $[48,49]$. BDNF may also be involved in the suppression of injury-induced delayed apoptosis [50], possibly through the increase of the antiapoptotic molecule, Bcl-xl [51]. An alternative mechanism for the neuroprotective effect of BDNF could be a BDNFregulated reduction of the number of terminal clubs formed at the distal axonal stumps in the rostral cord [52]. Terminal clubs are formed by continuous anterograde axonal transport after transection and sealing of the axon [53] and contain hydrolytic enzymes that contribute to nervous tissue loss [1,2,54]. This possible mechanism seems less likely because the amount of tissue loss was similar in all three implantation paradigms.

The effect of BDNF on survival of NeuN-positive cells was visible at 4 and 8 weeks after implantation, which may reflect the onset of degradation of the poly(D,L-lactic acid) foam. The poly(D,L-lactic acid) foam used in the present study contained PLA-b-poly(ethylene oxide) $4 \mathrm{k}-4 \mathrm{k}$ copolymer, which increases the absorption of water, e.g., the wettability of the foam [34]. However, it is difficult to foretell the in vivo degradation time of the polymer foam because it depends on the size, shape, and porosity of the foam, and the variability of the in vivo milieu, e.g., the injured adult spinal cord.

The finding that BDNF did not exert a neuroprotective effect in the caudal spinal cord stump may reflect differences between the rostral and caudal cord following transection and/or transplantation (see [55]). Here, the finding that BDNF did not influence neurons in the caudal stump may reflect differences in injury-induced damage to the blood supply to the caudal and rostral spinal cord stumps [56-59]. Possibly, the reduced blood flow has resulted in a diminished supply of oxygen and nutrients, which would result in an increased cell death (reviewed by [3]). Alternatively, the diminished blood flow may have prevented the supply of BDNF from the degrading foam to the caudal stump in high enough levels to promote an effect on neuronal survival. The implantation of foam containing BDNF increased the number of blood vessels at the mid-level of the implant compared to the control foam at 8 weeks after implantation. Blood vessels are formed by endothelial cells, which produce and secrete BDNF [60]. Also, BNDF is a known survival factor for endothelial cells, which express the trkB receptor [61]. Possibly, BDNF released from the implanted poly(D,L-lactic acid) foam has resulted in an increased number or in an increased proliferation of endothelial cells, which has resulted in the formation of a higher number of blood vessels. However, an effect of BDNF on endothelial cell migration and proliferation has not been demonstrated unambiguously in the injured adult rat spinal cord. The presence of FGF1 in the fibrin glue may also have contributed to the formation of blood vessels [62], which may explain the much higher numbers found in the fibrin glue only implant.

Tissue sparing at the rostral and caudal interface was similar in all groups. More tissue albeit not significantly was lost in the caudal stump compared with the rostral stump. It should be noticed that the total amount of tissue loss within both cord stumps was approximately $60 \%$ in the rostral and $65 \%$ in the caudal cord stump. The presence of fibrin glue with FGF1 may have contributed to the sparing of spinal nervous tissue. The rationale to embed the poly(D,L-lactic acid) foam within fibrin glue was to prevent possible abrasion of the vulnerable damaged spinal cord stump by the somewhat sturdy foam. In addition, the fibrin glue may serve as a structural support for the implant and as an adhesive medium for the implant and the spinal cord stump [63]. Also, FGF1 was added to the fibrin glue because it was shown to promote axonal regeneration and reduce neuronal death [11] and reduce axonal dieback [64]. Previous studies using rat models have demonstrated the important role of FGF1 in axonal regeneration in the injured adult spinal cord [11,64,65].

The number of NF-positive axons within both types of poly(D,L-lactic acid) foams was low compared with fibrin only implants, suggesting that the porous polymer structure supported only limited axonal ingrowth. One possible explanation for the low number of regenerating axons within the foam could be the lack of interconnected macropores. However, earlier it has been demonstrated, using impedance spectroscopy that relies 
upon measuring the ionic conduction of water-saturated foams, that the foams as used within the present study were highly porous and open on an interconnecting network of micropores [66]. In fact, the three-dimensional porous foams demonstrated adequate transport properties, which reflect a high pore interconnectivity [66]. Besides a low number of axons, the number of myelinated axons in the foams was also low compared to fibrin only implants. Overall, compared to both types of foam, a fibrin only implant resulted in a much better axonal regeneration response. This may reflect the fact that a fibrin only implant attracts a much higher number of Schwann cells than a foam implant. Using electron microscopy, some Schwann cells were found within the foams at all time points. Also, some of the Schwann cells in the foams were found to ensheath axons. Clearly, the polymer foam did not support the invasion of a high number of Schwann cells. Earlier, implantation of 14-20 rods, made of the same material as the foams in the present study, in between the cord stumps and embedded in fibrin glue with FGF1 following a complete transection of the adult thoracic spinal cord did promote axonal regeneration into the transplanted lesion site [34,35]. The difference with the present study may be that more fibrin glue with FGF1 will be present in between the small rods, which may result in a much better axonal growth response than with fibrin only in between the foam and the cord stumps.

BDNF containing foam results in a more rapid ingrowth of axons. Axons were present in BDNF-foam at 2 weeks after implantation, whereas at this time point control foam was lacking axons. Previously, BDNF has been shown to promote axonal regeneration into and from intraspinal grafts [18,25,27,40-42]. Clearly, the more rapid growth of axons into the BDNF containing foam may have resulted from the axonal growth-promoting properties of BDNF.

With retrograde tracing techniques we demonstrated that none of the axons within the foam grew into the caudal spinal cord in any of the three paradigms. This finding explains the lack of substantial hind limb functional improvements. In all three implantation paradigms the observed average improvements in hind limb function were largely similar. The BBB score was approximately 6 , which implies extensive movement of two hindlimb joints. Our results demonstrate that the presence of the polymer foam did not hinder functional improvements seen normally after a complete spinal cord transection. Also, the presence of the BDNF containing foam did not enhance functional recovery compared to the control foam. Ideally, for a more substantial and biological significant improvement of hind limb function in the injured and implanted adult rat spinal cord, descending axons, which are involved in locomotor function, have to regenerate across the implant and into the caudal cord where they need to form synaptic connections with target neurons.

In summary, our results demonstrated that poly(D,L-lactic acid) scaffolds are well tolerated in the transected adult rat spinal cord. The gliotic and inflammatory response is not beyond what is normally seen after transection/implantation in the cord and the amount of tissue loss is similar after implantation of foam or fibrin only. Moreover, the presence of BDNF in the foam has a neuroprotective effect on neurons in the rostral cord, results in a more rapid ingrowth of axons and in the formation of blood vessels in the foam. However, despite these effects, the overall axonal regenerative response is low and none of the responding axons grew from the foam into the caudal cord. Responsible for the low axonal growth response may be the limited presence of Schwann cells within the foam. The seeding of Schwann cells into the foam before implantation may result in an improved number and myelination of responding axons.

\section{Acknowledgements}

The authors are grateful to Krishna N. Tewari, Enrique P. Lopez, and John D. Campagna for help with histology; Annemarie N. Ali for help with image analysis; and Yelena Pressman for cell culture. Lyudmi-la Rusakova, Rosa M. Abril, Denise Koivisto and Kim E. Loor are thanked for their help with animal care and behavioral testing and Robert Camarena for assistance in photography. Dr. Maquet is postdoctoral researcher by the Fonds National de la Recherche Scientifique (F.N.R.S). CERM is indebted to the Services Fédéraux des Affaires Scientifiques, Techniques et Culturelles for financial support in the frame of the Poles d'Attraction Interuniversitaires: PAI 5/03. This work was funded by the Prinses Beatrix Fonds, Daniel Heumann Foundation, Florida State, and The Miami Project.

\section{References}

[1] Dusart I, Schwab ME. Secondary cell death and the inflammatory reaction after dorsal hemisection of the rat spinal cord. Eur J Neurosci 1994;6(5):712-24.

[2] Tator CH. Update on the pathphysiology and pathology of acute spinal cord injury. Brain Pathol 1995;5(4):407-13.

[3] Tator $\mathrm{CH}$, Fehlings MG. Review of the secondary injury theory of spinal cord trauma with emphasis on vascular mechanisms. $\mathrm{J}$

Neurosurg 1991;75:15-26.

[4] Bunge RP, Puckett WR, Hiester ED. Observations on the pathology of several types of human spinal cord injury, with emphasis on the astrocyte response to penetrating injuries. Adv Neurol 1997;72:305-15.

[5] Tuszynski MH, Gabriel K, Gerhardt K, Szollar S. Human spinal

cord retains substantial structural mass in chronic stages after injury. J Neurotrauma 1999;16:523-31. 
[6] Bunge MB. Bridging areas of injury in the spinal cord. Neuroscientist 2001;7:325-39.

[7] Ramon-Cueto A. Olfactory ensheathing glia transplantation into the injured spinal cord. Prog Brain Res 2000;128:265-72.

[8] Jones LL, Oudega M, Bunge MB, Tuszynski MH. Neurotrophic factors, cellular bridges and gene therapy for spinal cord injury. J Physiol 2001;533:83-9.

[9] Takami T, Oudega M, Bates ML, Wood PM, Kleitman N, Bunge MB. Schwann cell but not olfactory ensheathing glia transplants improve hindlimb locomotor performance in the moderately contused adult rat spinal cord. J Neurosci 2002;22(15):6670-81.

[10] Plant GW, Christensen CL, Oudega M, Bunge MB. Delayed transplantation of olfactory ensheathing glia promotes sparing/regeneration of supraspinal axons in the contused adult rat spinal cord. J Neurotrauma 2003;20(1):

[11] Cheng H, Cao Y, Olson L. Spinal cord repair in adult paraplegic rats: partial restoration of hindlimb function. Science 1996;273:510-3.

[12] Grill R, Murai K, Blesch A, Gage FH, Tuszynski MH. Cellular delivery of neurotrophin-3 promotes corticospinal axonal growth and partial functional recovery after spinal cord injury. J Neurosci 1997;17:5560-72.

[13] Ramon-Cueto A, Cordero MI, Santos-Benito FF, Avila J. Functional recovery of paraplegic rats and motor axon regeneration in their spinal cords by olfactory ensheathing glia. Neuron 2000;25:425-35.

[14] Iwashita Y, Kawaguchi S, Murata M. Restoration of function by replacement of spinal cord segments in the rat. Nature 1994;367: 16770 .

[15] Li Y, Field PM, Raisman G. Repair of adult rat corticospinal tract by transplants of olfactory ensheathing cells. Science 1997;277:20002.

[16] Liu Y, Kim D, Himes BT, Chow SY, Schallert T, Murray M, Tessler A, Fischer I. Transplants of fibroblasts genetically modified to express BDNF promote regeneration of adult rat rubrospinal axons and recovery of forelimb function. J Neurosci 1999;19:4370-87.

[17] McDonald JW, Liu XZ, Qu Y, Liu S, Mickey SK, Turetsky D, Gottlieb DI, Choi DW. Transplanted embryonic stem cells survive, differentiate and promote recovery in injured rat spinal cord. Nat Med 1999:5:1410-2.

[18] Coumans JV, Lin TT, Dai HN, MacArthur L, McAtee M, Nash C, Bregman BS. Axonal regeneration and functional recovery after complete spinal cord transection in rats by delayed treatment with transplants and neurotrophins. J Neurosci 2001;21(23): 9334-44.

[19] Bunge MB, Kleitman N. Neurotrophins and neuroprotection improve axonal regeneration into Schwann cell transplants placed in transected adult rat spinal cord. In: Tuszynski MH, Kordower JH, editors. CNS regeneration. New York: Academic Press; 1998. p. 631-45. [20] Oudega M, Gautier ES. Spinal cord repair strategies: Schwann cells, neurotrophic factors, and biodegradable polymers. Biomed Rev $1999 ; 10: 75-88$.

[21] Oudega M, Sagen J. Spinal cord. In: Methods of tissue engineering. New York: Academic Press; 2001. p. 1143-55.

[22] Xu XM, Guenard V, Kleitman N, Bunge MB. Axonal regeneration into Schwann cell seeded guidance channels grafted into transected adult rat spinal cord. J Comp Neurol 1995;351: 145-60.

[23] Xu XM, Chen A, Guenard V, Kleitman N, Bunge MB. Bridging Schwann cell transplants promote axonal regeneration from both the proximal and caudal stumps of transacted adult rat spinal cord. J Neurocytol 1997;26:1-16.

[24] Chen A, Xu XM, Kleitman N, Bunge MB. Methylprednisolone administration improves axonal regeneration into Schwann cell grafts in transected adult rat thoracic spinal cord. Exp Neurol 1996;138:261-76.

[25] Xu XM, Guenard V, Kleitman N, Aebischer P, Bunge MB. A combination of BDNF and NT-3 promotes supraspinal axonal regeneration into Schwann cell grafts in adult rat thoracic spinal cord. Exp Neurol 1995;134:261-72.

[26] Oudega M, Xu XM, Guenard V, Kleitman N, Bunge MB. A combination of insulin-like growth factor-I and platelet-derived growth factor enhances myelination but diminishes axonal regeneration into Schwann cell grafts in the adult rat spinal cord. Glia 1997;19:247-58.

[27] Menei P, Montero-Menei C, Whittemore SR, Bunge RP, Bunge MB. Schwann cells genetically modified to secrete human BDNF promote enhanced axonal regrowth across transected adult rat spinal cord. Eur J Neurosci 1998;10(2):607-21.

[28] Gautier SE, Oudega M, Fragoso M, Chapon P, Plant GW, Bunge MB, Parel J-M. Poly(a-hydroxyacids for application in the spinal cord: resorbability and biocompatibility with adult rat Schwann cells and spinal cord. J Biomed Mater Res 1998;42:642-54.

[29] Oudega M, Gautier SE, Chapon P, Fragoso M, Bates ML, Parel J-M, Bunge MB. Axonal regeneration into Schwann cell grafts within resorbable poly(a-hydroxyacid) guidance channels in the adult rat spinal cord. Biomaterials 2001;22:1125-36.

[30] Woerly S, Doan VD, Evans-Martin F, Paramore CG, Peduzzi JD. Spinal cord reconstruction using NeuroGel implants and functional recovery after chronic injury. J Neurosci Res 2001;66(6): 1187-97.

[31] Friedman JA, Windebank AJ, Moore MJ, Spinner RJ, Currier BL, Yaszemski MJ. Biodegradable polymer grafts for surgical repair of the injured spinal cord. Neurosurgery 2002;51(3):742-51.

[32] Teng YD, Lavik EB, Qu X, Park KI, Ourednik J, Zurakowski D, Langer R, Snyder EY. Functional recovery following traumatic spinal cord injury mediated by a unique polymer scaffold seeded with neural stem cells. Proc Natl Acad Sci USA 2002;99(5): 3024-9.

[33] Maquet V, Martin D, Malgrange B, Franzen R, Schoenen J, Moonen G, Jérôme R. Peripheral nerve regeneration using bioresorbable macroporous polylactide scaffolds. J Biomed Mater Res2000;52(4):639-51.

[34] Maquet V, Martin D, Scholtes F, Franzen R, Schoenen J, Moonen G, Jerome R. Poly(D,L-lactide) foams modified by poly(ethylene oxide)-block-poly(D,L-lactide) copolymers and a-FGF: in vitro and in vivo evaluation for spinal cord regeneration. Biomaterials 2001;22:1137-46

[35] Blacher S, Maquet V, Schils F, Martin D, Schoenen J, Moonen G, Jerome R, Pirard J-P. Image analysis of the axonal ingrowth into poly(D,L-lactide) porous scaffolds in relation to the 3-D porous structure. Biomaterials 2003;24(6): 1033-44.

[36] Diener PS, Bregman BS. Neurotrophic factors prevent the death of CNS neurons after spinal cord lesions in newborn rats. Neuroreport 1994;5(15): 1913-7.

[37] Novikova L, Novikov L, Kellerth JO. Brain-derived neurotrophic factor reduces necrotic zone and supports neuronal survival after spinal cord hemisection in adult rats. Neurosci Lett 1996; 220(3):203-6.

[38] Yuan Q, Wu W, So KF, Cheung AL, Prevette DM, Oppenheim RW. Effects of neurotrophic factors on motor neuron survival following axonal injury in newborn rats. Neuroreport 2000; 11(10):2237-41.

[39] Novikova LN, Novikov LN, Kellerth JO. Differential effects of neurotrophins on neuronal survival and axonal regeneration after spinal cord injury in adult rats. J Comp Neurol 2002;452(3): 255-63.

[40] Bregman BS, McAtee M, Dai HN, Kuhn PL. Neurotrophic factors increase axonal growth after spinal cord injury and transplantation in the adult rat. Exp Neurol 1997;148(2):475-94.

[41] Oudega M, Hagg T. Neurotrophins promote regeneration of sensory axons in the adult rat spinal cord. Br Res 1999;818:431-8.

[42] Jin Y, Fischer I, Tessler A, Houle JD. Transplants of fibroblasts genetically modified to express BDNF promote axonal regeneration from supraspinal neurons following chronic spinal cord injury. Exp Neurol 2002;177(1):265-75.

[43] Teng YD, Mocchetti I, Wrathall JR. Basic and acidic fibroblast growth factors protect spinal motor neurons in vivo after experimental spinal cord injury. Eur J Neurosci 1998;10(2): 798-802.

[44] Lee YS, Baratta J, Yu J, Lin VW, Robertson RT. AFGF promotes axonal growth in rat spinal cord organotypic slice co-cultures. J Neurotrauma 2002; 19(3): 357-67.

[45] Mullen RJ, Buck CR, Smith AM. NeuN, a neuronal specific nuclear protein in vertebrates. Develop 1992;116(1):201-11.

[46] Beattie MS, Farooqui AA, Bresnahan JC. Review of current evidence for apoptosis after spinal cord injury. J Neurotrauma 
2000;17(10):915-25.

[47] Beattie MS, Hermann GE, Rogers RC, Bresnahan JC. Cell death in models of spinal cord injury. Prog Brain Res 2002;137:37-47. [48] Egea J, Espinet C, Soler RM, Dolcet X, Yuste VJ, Encinas M, Iglesias M, Rocamora N, Comella JX. Neuronal survival induced by neurotrophins requires calmodulin. J Cell Biol 2001; 154(3): 585-98.

[49] Cheng A, Wang S, Yang D, Xiao R, Mattson MP. Calmodulin mediates brain-derived neurotrophic factor cell survival signaling upstream of Akt kinase in embryonic neocortical neurons. J Biol Chem 2003;278(9):7591-9.

[50] Koda M, Murakami M, Ino H, Yoshinaga K, Ikeda O, Hashimoto M, Yamazaki M, Nakayama C, Moriya H. Brain-derived neurotrophic factors suppress delayed apoptosis of oligodendrocytes after spinal cord injury in rats. J Neurotrauma 2002;19(6):777-85.

[51] Qiu J, Nesic O, Ye Z, Rea H, Westlund KN, Xu GY, McAdoo D, Hulsebosch CE, Perez-Polo JR. Bcl-xL expression after contusion to the rat spinal cord. J Neurotrauma 2001;18(11):1267-78.

[52] Sayer FT, Oudega M, Hagg T. Neurotrophins reduce degeneration of injured ascending sensory and corticospinal motor axons in adult rat spinal cord. Exp Neurol 2002;175(1):282-96.

[53] Kao CC, Chnag LW, Bloodworth JM. Electron microscopic observations of the mechanisms of terminal club formation in transected spinal cord axons. J Neuropathol Exp Neurol 1977; 36:140-56.

[54] Kao CC, Chnag LW, Bloodworth JM. The mechanisms of spinal cord cavitation following spinal cord transection. Part 2. Electron microscopic observations. J Neurosurg 1977;46:745-56.

[55] Plant GW, Bates ML, Bunge MB. Inhibitory proteoglycan immunoreactivity is higher at the caudal than the rostral Schwann cell grafttransected spinal cord interface. Mol Cell Neurosci 2001;17(3):471—87.

[56] Wallace MC, Tator CH. Spinal cord blood flow measured with microspheres following spinal cord injury in the cat. Can J Neurol Sci 1986;13:91-6.

[57] Imperato-Kalmar EL, McKinney RA, Schnell L, Rubin BP, Schwab ME. Local changes in vascular architecture following partial spinal cord lesion in the rat. Exp Neurol 1997;145:322-8.

[58] Mautes AE, Weinzierl MR, Donovan F, Noble LJ. Vascular events after spinal cord injury: contribution to secondary pathogenesis. Phys Ther 2000;80(7):673-87.

[59] Koyanagi I, Tator CH, Theriault E. Silicone rubber microangiography of acute spinal cord injury in the rat. Neurosurg 1993;32:260-8 [60] Nakahashi T, Fujimura H, Altar CA, Li J, Kambayashi J, Tandon NN, Sun B. Vascular endothelial cells synthesize and secrete brainderived neurotrophic factor. FEBS Lett 2000; 470(2): 113-7.

[61] Donovan MJ, Lin MI, Weign P, Ringstedt T, Kraemer R, Hahn R, Wang S, Ibanez CF, Rafii S, Hempstead BL. Brain derived neurotrophic factor is an endothelial cell survival factor required for intramyocardial vessel stabilization. Development 2000; 127(21):453 $1-40$.

[62] Xue L, Greisler HP. Angiogenic effect of fibroblast growth factor-1 and vascular endothelial factor and their synergism in a novel in vitro quantitative fibrin-based 3-dimensional angiogenesis system. Surgery 2002;132(2):259-67.

[63] Robinson GA, Madison RD. Survival of adult rat retinal ganglion cells with regrown axons in peripheral nerve grafts: a comparison of graft attachment with suture of fibrin glue. J Neurosurg 2000;93(2):275-8

[64] Guest JD, Hesse D, Schnell L, Schwab ME, Bunge MB, Bunge RP. Influence of IN-1 antibody and acidic FGF-fibrin glue on the response of injured corticospinal tract axons to human Schwann cell grafts. J Neurosci Res 1997;50(5):888-905.

[65] Lee YS, Hsiao I, Lin VW. Peripheral nerve grafts and aFGF restore partial hindlimb function in adult paraplegic rats. J Neurotrauma 2002;19(10):1203-16.

[66] Maquet V, Blacher S, Pirard R, Pirard J-P, Jerome R. Characterization of porous polylactide foams by image analysis and impedance spectroscopy. Langmuir 2000; 16: 10463-70.

[67] Basso DM, Beattie MS, Bresnahan JC. A sensitive and reliable locomotor rating scale for open field testing in rats. J Neurotrauma 1995;12:1-21.

[68] Basso DM, Beattie MS, Bresnahan JC. Graded histological and locomotor outcomes after spinal cord contusion using the NYU weightdrop device versus transection. Exp Neurol 1996; 139: 244-56. 